A REFORMULAÇÃO DO PROJETO PEDAGÓGICO DE CURSOS DE LICENCIATURA EM UM INSTITUTO

FEDERAL: na mira(gem) de uma educação politécnica?

THE REFORMULATION OF THE PEDAGOGICAL PROJECT OF UNDERGRADUATE COURSES AT A FEDERAL INSTITUTE: in the sight(gem) of a polytechnical education?

\section{LA REFORMULACIÓN DEL} PROYECTO PEDAGÓGICO DE CURSOS DE PREGRADO EN UN INSTITUTO FEDERAL: ¿en la misma (gem) de una educación politécnica?

Resumo: Partindo do pressuposto políticopedagógico da defesa da formação profissional a partir do conceito de educação politécnica, este trabalho, ao conceber a formação inicial dos professores como um espaço privilegiado de concretização de uma educação para a emancipação e autonomia do ser humano, está organizado em duas partes: na primeira, discorre-se sobre a centralidade da compreensão de educação politécnica e do currículo e de seus atos enquanto subsunção à um projeto societário que rompa os limites do capital. Na segunda parte, discutem-se dados empíricos advindos de entrevistas e questionários semiabertos respondidos por professores de cursos de licenciaturas do Instituto Federal de Goiás, bem como os objetivos formativos circunscritos em seus respectivos projetos pedagógicos. Em síntese, a discussão dos dados produzidos a partir da categoria "(re)elaboração do currículo" evidencia cinco atos, dois quais três são proximais (estando, portanto, na mira) dos pressupostos educacionais da perspectiva politécnica, e já os outros dois, distais (na miragem), pois revelam a coadjuvantivação do envolvimento de parte dos docentes que não integram os Núcleos Docentes Estruturantes, quiça, assim como a participação dos estudantes, trabalhadoresprofessores em processo de formação inicial.

Palavras-chave: Formação de professores. Educação politécnica. Atos de currículo. Omnilateralidade.
Daniella de Souza Bezerra

Doutora em Educação

Professora do Instituto Federal de Educação, Ciência e Tecnologia de Goiás, Brasil.

E-mail: daniella.bezerra@ifg.edu.br Orcid: https://orcid.org/0000-0001-63999120

Como citar este artigo:

BEZERRA, D. S. A REFORMULAÇÃO DO PROJETO PEDAGÓGICO DE CURSOS DE LICENCIATURA EM UM INSTITUTO FEDERAL: na mira(gem) de uma educação politécnica?. Revista Espaço do Currículo, v. 14, n. 2, p. 1-12, 2021. ISSN1983-1579. DOI: https://doi.org/10.22478/ufpb.1983$1579.2021 \mathrm{~V} 14 \mathrm{n} 2.59550$. 
Abstract: Departing from the political-pedagogical assumption of defending professional training from the concept of polytechnic education, this work, by conceiving initial teacher training as a privileged space for implementing an education for the emancipation and autonomy of the human being, is organized in two parts: in the first, the centrality of understanding polytechnic education and the curriculum and its actions is discussed as a subsumption of a societal project that breaks the limits of capital. In the second part, empirical data from interviews and semi-open questionnaires answered by professors of undergraduate courses at the Federal Institute of Goiás are discussed, as well as the training objectives circumscribed in their respective pedagogical projects. In summary, the discussion of the data produced from the category "(re)preparation of the curriculum" shows five acts, two of which three are proximal (and therefore in the crosshairs) of the educational assumptions of the polytechnic perspective, and the other two, distal (in the mirage), as they reveal the supporting involvement of part of the teachers who are not part of the Structuring Teachers Nucleus, perhaps, as well as the participation of students, workers-teachers in the initial training process.

Keywords: Teacher training. Polytechnic education. Curriculum Acts. Omnilaterality.

Resumem: Partiendo del supuesto político-pedagógico de defender la formación profesional desde el concepto de educación politécnica, este trabajo, al concebir la formación inicial docente como un espacio privilegiado para implementar una educación para la emancipación y autonomía del ser humano, se organiza en dos partes: en el primero, se discute la centralidad de entender la educación politécnica y el currículo y sus acciones como subsunción de un proyecto social que rompe los límites del capital. En la segunda parte se discuten datos empíricos de entrevistas y cuestionarios semiabiertos respondidos por profesores de cursos de pregrado del Instituto Federal de Goiás, así como los objetivos formativos circunscritos en sus respectivos proyectos pedagógicos. En resumen, la discusión de los datos producidos a partir de la categoría "(re) elaboración del currículo" muestra cinco actos, dos de los cuales tres son proximales (y por tanto en la mira) de los supuestos educativos de la perspectiva politécnica, y el otro dos, distal (en el espejismo), ya que revelan la implicación de apoyo de parte de los docentes que no forman parte del Núcleo Estructurador Docente, quizás, así como la participación de estudiantes, trabajadores-docentes en el proceso de formación inicial.

Palabras clave: Formación docente. Educación politécnica. Actos curriculares. Omnilateralidad.

\section{INTRODUÇÃO}

Desde 2008, um quinto das vagas ofertadas pelos Institutos Federais de Educação, Ciência e Tecnologia são, legalmente, destinadas a formar trabalhadores para outros os espaços do mundo do trabalho, qual seja, a escola de educação básica e educação profissional. Partindo-se do pressuposto de que os projetos políticos pedagógicos dessas instituições concebem o trabalho enquanto princípio educativo, este estudo se ocupou de investigar os atos de currículo de agentes de formação de professores de cursos de licenciaturas ofertados por um Instituto Federal do estado de Goiás, procurando indiciar se e em que medida o currículo vivido (atos de currículo) se compromete com a formação de professores na perspectiva de educação politécnica.

A escolha do objeto deste estudo se funda no pressuposto de que cabe ao professor organizar o processo educativo de tal modo a possibilitar ao estudante a apropriação da cultura historicamente elaborada pela humanidade, possibilitando tanto a sua expansão em múltiplas dimensões (omnilateralidade) quanto seu compromisso com uma alternativa institucional e societária que não se conforme e reproduza a lógica do capital (MÉSZÁROS, 2008). Esse pressuposto tem também seu substrato teórico na pedagogia histórico-crítica, pela qual a atividade educativa não prescinde de uma formação do professor com bases sólidas, fundamentada em conhecimentos científicos (SAVIANI, 2012), a partir de uma compreensão materialista-histórica da realidade concreta.

É, então, sob a égide de uma concepção politécnica de educação (SAVIANI, 1989) que o processo inicial de formação de professores deveria se alicerçar, comprometendo-se, radicalmente, e intercambiando-se com práticas educacionais mais abrangentes envolvidas com a tarefa de mudar as condições objetivas de reprodução metabólica social, assim como com a automudança consciente dos indivíduos (MÉSZÁROS, 2008, p 65). 
Nessa senda, uma educação politécnica pressupõe que no processo formativo ocorra a plena expansão do indivíduo humano (omnilateralidade), bem como se insere dentro de um projeto de desenvolvimento social de ampliação dos processos de socialização, não se restringindo ao sentido unilateral, interessado e imediato do mercado de trabalho. Ela guarda relação com as potencialidades libertadoras do desenvolvimento das forças produtivas assim como com a negação destas (MACHADO,1997). Liga-se, portanto, à perspectiva de ruptura com a divisão do trabalho capitalista enquanto fundamento da sociabilidade humana.

Apoiados na defesa da formação profissional a partir do conceito de educação politécnica, o este trabalho, ao conceber a formação inicial dos professores, no âmbito das licenciaturas, como uma "esfera privilegiada de concretização de uma educação para a emancipação e autonomia do ser humano" (SILVA, 2011, p.13), está organizado em duas partes: na primeira, discorre-se sobre a centralidade da compreensão de educação para emancipação humana e do currículo e de seus atos enquanto subsunção à um projeto societário que rompa os limites do capital. Na segunda parte, discutem-se dados empíricos advindos de entrevistas e questionários semiabertos respondidos por professores de cursos de licenciaturas de um Instituto Federal do estado de Goiás, bem como seus respectivos projetos pedagógicos com o afinco de indiciar um possível compromisso com a formação de professores na perspectiva politécnica. Trata-se, aqui, de estudo qualitativo com enfoque materialista-histórico (TRIVINÕS, 2017).

Os pressupostos de que partimos não são pressupostos arbitrários, dogmas, mas pressupostos reais, de que só se pode abstrair na imaginação. São os indivíduos reais, sua ação e suas condições materiais de vida, tanto aquelas por eles já encontradas como as produzidas por sua própria ação. Esses pressupostos são, portanto, constatáveis por via puramente empírica. (MARX; ENGELS, p.2007, p.87).

Outrossim, sob a perspectiva do materialismo histórico-dialético, procurou-se conduzir a análise dos dados produzidos. Nessa mira, parte-se também do pressuposto teórico de que a prática social é o critério de verdade (TRIVIÑOS, 2017) para "mensurar" os efeitos concretos de um processo formativo comprometido com uma educação politécnica.

\section{SOBRE CONCEPÇÕES DE EDUCAÇÃO POLITÉCNICA, CURRÍCULO E ATOS DE CURRÍCULO}

Um projeto de educação na perspectiva politécnica demarca as coordenadas e princípios de uma formação que esteja a serviço de uma educação "desinteressada", ou seja, uma educação que aspire para além das necessidades imediatas do mercado (GRAMSCl, 2001). Também terá como princípios fundantes "a categoria trabalho, a relação teoria e prática, a pesquisa na/da formação e a função docente" (SILVA, 2011, p.16).

Nessa direção, os principais direcionamentos dados pela concepção educação politécnica, i.e., uma concepção marxiana e marxista de educação, são:

1. Educação pública, gratuita, obrigatória e única para todas as crianças e jovens, de forma a romper com o monopólio por parte da burguesia da cultura, do conhecimento.

2. A combinação da educação (incluindo-se aí a educação intelectual, corporal e tecnológica com a produção material com o propósito de superar o hiato historicamente produzido entre trabalho manual (execução, técnica) e trabalho intelectual (concepção, ciência) e com isso proporcionar a todos uma compreensão integral do processo produtivo.

3. A formação omnilateral (isto é, multilateral, integral) da personalidade de forma a tornar o ser humano capaz de produzir e fruir ciência, arte, técnica.

4. A integração recíproca da escola à sociedade com o propósito de superar o estranhamento entre as práticas educativas $e$ as demais práticas sociais. (RODRIGUES, 2009, p.1, Grifos nossos). 
Caberia, portanto, à educação dar aos homens as ferramentas de aglutinação social e escolar, o inter-relacionamento entre o pensar e o agir, possibilitando, inclusive, conhecimentos para além da estrutura dominante do capital, com vistas a emancipá-los em sua omnilateralidade. O princípio de uma teoria educacional marxista comporta um ensino omnilateral que leve o indivíduo multifacetado à humanização tendo no horizonte a totalidade.

O termo politecnia, não obstante denotar, literalmente, múltiplas técnicas, multiplicidade de técnicas o que pode culminar no risco de compreender esse conceito como "a totalidade das diferentes técnicas fragmentadas, autonomamente consideradas" (SAVIANI, 2003), está na literatura da área de Trabalho e Educação no Brasil para se referir ao domínio dos fundamentos científicos das diferentes técnicas que caracterizam o processo de trabalho produtivo moderno.

Parte-se aqui da compreensão de Quelhas e $\operatorname{Nozaki}(2006$, p. 1) de que a consolidação da identidade profissional do professor politécnico não prescinde de uma formação inicial que se funde na(o):

1) sólida formação teórica de base multidisciplinar e interdisciplinar na perspectiva da formação omnilateral;

2) unidade entre teoria/prática, que significa assumir uma postura em relação a produção do conhecimento científico que impregna a organização curricular dos cursos, tomando o trabalho como princípio educativo e como práxis social

3) gestão democrática - que permitam a vivência e o trabalho com relações de poder democráticas, e não autoritárias;

4) compromisso social com ênfase na concepção sócio-histórica do trabalho, estimulando análises políticas sobre as lutas históricas pela superação da sociedade de classes, para que seja garantido o acesso aos bens a todos que dele participam em sua produção, especificamente no campo da cultura corporal;

5) trabalho coletivo, solidário e interdisciplinar, o trabalho pedagógico como eixo articulador do conhecimento para a formação omnilateral;

6) formação continuada para permitir a relação entre a formação inicial e continuada no mundo do trabalho;

7) avaliação permanente como parte integrante das atividades curriculares, de responsabilidade coletiva a ser conduzida à luz do projeto político pedagógico da instituição, abarcando as dimensões da avaliação da aprendizagem, do docente, dos programas e projetos, da instituição.

No que concerne à concepção de currículo, compreende-se, com base em Macedo (2013, p.426), que ele se refere ao "conhecimento eleito como formativo". Trata-se de um artefato socioeducacional que se configura nas ações de conceber/selecionar/produzir, organizar, institucionalizar, implementar/dinamizar saberes, conhecimentos, atividades, competências e valores visando uma "dada" formação, constituída por processos e construções forjados na relação com o conhecimento eleito como formativo.

Professores e educadores em geral, nos seus cenários formativos, atualizam, constroem e dão feição ao currículo, cotidianamente, relacionalmente, tendo como seu principal objetivo a formação e seus processos de interpretação e veiculação, daí sua inerente complexidade. Há uma costura, uma forma de tecer a formação cuja compreensão não é possibilitada por documentos educacionais, não só a proposta curricular, digam muito sobre o currículo, sua concepção e prática. (MACEDO, 2011, p.26).

Enquanto uma construção social, e articulado de perto com outros processos e procedimentos pedagógico-educacionais, o currículo, como qualquer artefato educacional, atualiza-se - os atos de currículo- de forma ideológica e, neste sentido, veicula "uma" formação ética, política, estética e cultural, 
nem sempre explícita, nem sempre coerente, nem sempre absoluta, nem sempre sólida. (MACEDO, 2011, p.25)

Portanto, por atos de currículo, compreendemos a ação concreta, praticada por alguém situado.

Ato, em Bakhtin, não se resume, portanto, nem a akt (ato puro simples), nem a tat (ação), do alemão filosófico. Bakhtin conjuga akt ao termo russo deiatel'nost para significar ato/atividade. Assim, a experiência no mundo humano é sempre mediada pelo agir situado e avaliativo do sujeito, ao qual ele confere sentido a partir do mundo como materialidade concreta. $\mathrm{O}$ ato, portanto, postula, cria. (MACEDO, 2011, p. 46).

Nessa linha, assumimos que os atos de currículo tem papel fundamental da formação de professores dos Institutos Federais. Enquanto atos situados, é mister privilegiar o processo, e não o produto, em que se constituíram e a responsabilização. Focar agora nos atos de currículos nos dará a dimensão de que as dinâmicas formativas se instituem é no fazer cotidiano a partir de nossas relações configurando como "práxis epistemológico-formativa" (MACEDO, 2011, p.98).

\section{DOS ATOS DE CURRÍCULO CONCRETOS AO PROJETO SOCIETÁRIO CENTRADO NO HOMEM}

Este estudo constitui uma investigação de natureza qualitativa (OLIVEIRA, 2007), cujos instrumentos de coleta de dados foram entrevistas e questionários aplicados, presencialmente, a 12 (doze) formadores de professores de cursos de licenciatura dos campi Aparecida de Goiânia, Cidade de Goiás, Itumbiara, Jataí, Luziânia e Uruaçu do Instituto Federal de Goiás, que assentiram a participar deste estudo em 2016. Para subsidiar a análise, foram também analisados os Projetos Pedagógicos dos Cursos (PPC) de licenciaturas ofertados pelos campi dos informantes, especificamente no que pese aos objetivos formativos do processo de formação inicial de professores. Isso dito, nesta subseção, são apresentadas e discutidas os atos de currículo advindos, especificamente, dos processos de (re) definição do conteúdo eleito como formativo, isto é, o currículo, dos cursos de licenciaturas.

No âmbito das práticas educacionais, todos os envolvidos (professores, gestores, estudantes) nas coisas do currículo são capazes de ressignificar, construir e constituir o conhecimento eleito como formativo nesses cenários curriculares, sendo todos curriculantes. Nesse sentido, a fala dos informantes diz respeito ao protagonismo por parte do corpo docente do curso de licenciatura no que tange a definição do currículo, quais são os envolvidos e interessados na definição das atividades formativas do curso de licenciatura, e se esses envolvidos tem o direito de construir o currículo e os anseios por definições de autoridades educacionais.

Considerando essa primeira categoria de análise, os dados evidenciam que há significativo envolvimento do corpo docente dos cursos de licenciatura investigados no que tange a definição do conteúdo formativo (currículo), conforme podemos observar excertos de entrevistas com seis professores:

A-L: ${ }^{1}$ Você considera que em seu campus há protagonismo por parte do corpo docente do curso de licenciatura no que tange a definição do currículo, e quem são os envolvidos e interessados nas atividades formativas do curso de licenciatura?

B-P1: "Eu acho que o protagonismo maior é dos professores, os alunos têm participado mesmo porque alguns representantes dos alunos são eleitos, algumas comissões que pensam nas atividades no Campus, mas é mais pelo lado dos professores" [...]

C-P2: "[...] o protagonismo é mesmo dos professores. A estrutura mesmo do instituto, ela é montada em cima da decisão, e na elaboração a partir dos

"A letra "L" se refere à fala da pesquisadora, e as demarcadas com a letra " $P$ " se referem a um dos professores informantes. 
professores".

D-P3: "Sim, todas as decisões do campo são feitas de forma conjunta, então nas reuniões diárias os professores trazem as necessidades, [...] Os docentes, chefe de departamento, coordenação, a equipe mesmo do curso de licenciatura, mas docentes participam muito tudo é definido em reuniões com os docentes. [...] a gente quer liberdade e autonomia pra adequar a matriz curricular a nossa realidade, nós já fizemos esse estudo no ano passado várias reuniões, discutimos elaboramos ementa uma matriz curricular de acordo com a nossa necessidade e realidade, foi pra Goiânia e ai não foi aprovado nós gostaríamos de ter mais autonomia e o campus fala que dá autonomia, fizemos uma matriz curricular eles vedam então manda para reformular, temos que fazer algo que seja aprovado por Goiânia e isso limita um pouco.[...] procuramos seguir sim as orientações, procurando adequar dentro das possibilidades as necessidades do campus, mas querendo ou não nós temos que seguir os parâmetros, nós seguimos sim. [...] Tem o direito e o dever porque nós professores que formamos os novos professores nós temos que ter essa visão somos nós que temos de deliberar ou pelo menos planejar aquilo que seria o ideal porque nós estamos em contato direto com a realidade"

E-P4: Sim, é inclusive a semana passada nós nos reunimos o grupo para poder conversarmos é sobre um a proposta de um novo currículo, todos estão envolvidos nesse processo e essa mudança tá acontecendo na verdade que eu acredito com o envolvimento de todos tanto grupo docente, como de servidores, como pessoal terceirizado, a parte de setor administrativo enfim a parte de da reitoria em Goiânia todos é um trabalho em conjunto. Não, acho que seria definido por autoridades educacionais, na verdade todo currículo você tem que ter uma base né, você tem que ter um parâmetro porque muitas vezes há realidade de um estado não é igual a realidade de outro estado. Eu falo que tem coisas que precisam ser definidas é por autoridades educacionais e por instâncias maiores como o MEC.

F- P5: sempre houve participação, sempre convidamos, se prontificaram a participar, nunca foi imposição da administração. [...] Só os professores mesmo da base da química, mas a gente também envolve os professores do núcleo comum os matemáticos, os físicos [...] A gente segue as orientações do MEC, a gente tem muita dificuldade com isso buscado seguir o que o MEC orienta, na medida do possível dentro do nosso curso, mas a gente está conseguindo adequar, mas é assim, sempre é convocado reunião para discutir isso. E há discussão mesmo, conversas.

G-P6: Os envolvidos são normalmente colegiado, coordenação do curso com todos os professores que são da área de formação, e também das pessoas que trabalham nesse curso de outras disciplinas de outras áreas, os envolvidos $e$ interessados seriam os professores, todos que atuam no curso mas realmente na área da específica da licenciatura em física e alunos são convidados a participar também da reunião [...] eu vejo muito esse envolvimento um grupo de professores da área específica [...] O que eu percebo é se você tem uma nova lei que surge pra prática de ensino, a gente observa mais que tem uma preocupação em obedecer aquela lei mas, há momentos no curso que eu vejo que tem abertura pra discutir algumas situações que não seja assim pelas autoridades educacionais discutem mais a prescrições curriculares parâmetros curriculares observando aqui o colegiado talvez precisa de mais maturidade de uma orientação melhor por parte do núcleo docente estruturante, mais gestão acadêmica do campus por exemplo pra que se possa posicionar melhor com em relação as 
diretrizes curriculares, os parâmetros curriculares e votando a dizer, o colegiado não tem muita rotina não tem muita determinação de discussões mais aprofundadas nas práticas pedagógicas[...]uma rotina de discussão sobre esses parâmetros acho que deveria ter mais, é até uma crítica que eu faço [...] eu acho que as pessoas que estão envolvidas na formação do futuro professor eles tem o direito e o dever de construir o currículo.

Por meio do excertos B-P1, C-P2, D-P3, E-P4, F-P5 e G-P6, evidencia-se que há interesse e comprometimento dos professores formadores em construir, coletivamente, o currículo dos cursos. Mesmo em face de imperativos de revisão advindos de normativa do Conselho Nacional de Educação (vide excerto de F-P5 e G-P6) e/ ou de diligência emanada de setor institucional superior (Vide excerto D$\mathrm{P}_{3}$ ), os professores formadores não se abstém de sua autonomia de co-definir o conteúdo formativo dos licenciandos. Tais atos, portanto, revelam, concretamente, elementos configuradores de um processo formativo de professores politécnicos, como elencaram Quelhas e Nozaki (2006).

No pese aos agentes envolvidos e interessados na proposição de atividades formativas nos curso de licenciatura, excertos advindos das entrevistas mostram evidências de engajamento coletivo e colegiado por meio, por exemplo, do núcleo docente estruturante, conforme podemos observar nos excertos das entrevistas de H-P1 e I-P2:

H- P1: “Os coordenadores, o NDE dos cursos né?! O Núcleo Docente Estruturante, eu acho que é bastante ativo".

I- P2: "Embora eu estar há pouco tempo, o que tem chegado a mim, coisa que desde a criação do curso todas as decisões, toda a direção do curso em si, são decisões sempre coletivas".

Em resposta ao questionário semiaberto, metade dos 12 (doze) respondentes também destacaram o protagonismo do corpo docente no que tange a definição do currículo, i.e., do conhecimento eleito como formativo. Por outro lado, um terço considera não experienciar a autodeterminação dos colegas docentes nesses processo, e o outro um terço considera que o comprometimento é parcial.

No que pese aos processo de revisão dos projetos pedagógicos do curso, excertos das entrevistas evidenciam que o conteúdo eleito como formativo é revisto tanto por força de alterações das diretrizes curriculares nacionais (excerto J- P1) quanto por autodeterminação do colegiado local (Excerto de L-P2).

J-P1: [...] o curso foi criado em agosto de 2013, eu participei da elaboração, do seu primeiro formato, e ... a maioria dos professores daqui também participaram, esse projeto passou por uma reestruturação, para atender algumas questões formais, que estão numa fase de reconhecimento do curso né?! Pelo MEC, e nesse sentido nós estamos sempre tentando melhorar né?

L-P2: [...] os alunos não passaram pelo TCC ainda, a partir do semestre que vem que vai começar a ter, vai completar as quatro turmas. Então é muita coisa que não tá totalmente consolidada, tanto no seu perfil de aluno, seu perfil de pesquisa, então tudo isso juntando com o, fato de que a gente ainda tem que ser reconhecido pelo MEC. Tem ajustar uma coisa ali e tal, a gente tá nesse momento mesmo discutindo essas coisas, como o XXX falou o currículo não pode ficar terminado nunca a gente tem sempre que ir se adaptando, sempre melhorando, sempre evoluindo, não é constante, mas mesmo tempo o currículo do curso está terminando de restituir.(GRIFOS NOSSOS)

Considerando que o currículo indica caminhos, travessias e chegadas, que são constantemente realimentados e reorientados pela ação dos atores/ autores da cena curricular (MACEDO, 2011, p.27), os professores formadores, quando indagados por meio do questionário se consideravam que a formação inicial se constituía como uma esfera privilegiada de concretização de uma educação para a emancipação e autonomia do ser humano, foram unânimes quanto ao compromisso da primeira etapa da educação profissional para somar esforços no sentido de um projeto de sociedade alternativo ao que submete a 
sociedade hoje à lógica estrita do capital.

Ao se tratar sobre quem são os responsáveis pela definição do conhecimento eleito como formativo (currículo), os professores respondentes (vide excertos M-P1 e N-P2) consideraram que essa tarefa é de todos os envolvidos no cenário de formação de professores, inclusive os estudantes. Apesar de a necessidade de participação de todos ter sido declarada, não há quaisquer menção sobre a forma de envolvimento de outros envolvidos no processo formativo.

M-P1: [...] ]eu creio que tanto a comunidade externa quanto a comunidade interna são responsáveis por isso mais não, vejo isso acontecer... Em relação a responsabilidade pela formação dos nossos licenciandos, é sobretudo dos professores, mas eu vejo necessário um maior engajamento também dos próprios alunos também né?!

N-P2: [...] quanto mais amplo possível a comunidade puder participar, professores com seu conhecimento técnico da área, os alunos que vão se beneficiar dessa formação, professores, a comunidade, e todos deveriam tá participando opinando, colocando qual que é o sentido dessa formação, que tipo de professor nós queremos pra atuar na nossa comunidade. (Grifos nossos)

Os atos curriculares emanados desses excertos compreendem que "é dever dos docentes abrir os currículos para enriquece-los com novos conhecimentos e garantir o seu próprio direito e o dos alunos à risca, atualizada e diversa produção de conhecimentos e de leituras e significados" (ARROYO, 1999, p.37). Além da responsabilidade dos professores formadores e estudantes, as excertos M-P1 e N-P2 não se esquivaram de reconhecer o papel da comunidade externa à instituição no processo de (re)definição do conteúdo eleito como formativo. Esse ato revela a abertura desses agentes curriculares para o intercâmbio com outras práticas educativas na sociedade, contribuindo, portanto, para a ampliação e materialização de uma formação profissional que não se restrinja ao limites do capital.

Essa compreensão poderá subsidiar professores e estudantes na direção de uma educação que busque romper com os procedimentos pedagógicos que reforçam a unilateralidade do homem presente no capitalismo, e que construa uma perspectiva que vise ao pleno desenvolvimento do ser humano como condição para a construção de uma outra sociedade desvencilhada do sociometabolismo do capital. Para esse sentido, a tomada de consciência sobre os processos de desumanização já é e será um movimento fundamental para a compreensão da necessidade histórica de fortalecimento da luta de classes, isso porque, como alertado por Marx (2013), não basta interpretar o mundo, é preciso transformá-lo".

Ao serem indagados sobre a realidade concreta dos estudantes, os professores formadores demostraram em seus atos curriculares (vide, por exemplo, os excertos das entrevistas de P-P2 e Q-P3) ciência de que as condições econômicas e culturais, apesar de terem obstaculizado seu acesso e desfrute da produção material da humanidade, não são definidoras de suas potencialidades e capacidade para contribuir com a mudança desses condições para si e para os demais seres humanos. Inobstante em um atos (O-P1), essas condições são consideradas "na medida do possível". Esse excerto dista de uma perspectiva educacional politécnica e se aproxima da compreensão de currículo enquanto campo em disputa (ARROYO, 2011).

P-P2: "o currículo de licenciatura hoje ele leva em consideração a realidade histórico social sócio econômica mas acho que ele poderia levar mais [...] normalmente o aluno de licenciatura ele não é de uma classe que tem maior poder financeiro [...] a matriz curricular ele exige muito do aluno, pra que você tenha uma formação pelo menos de boa qualidade dum licenciando tem que ter um currículo que leva a sério a realidade sócio cultural e econômica, o currículo tem que levar em consideração todos esses fatores o que o aluno já traz com ele, acho isso muito bom um grupo de pessoas que coordena o curso dar uma boa formação técnica ou formação naquela área que ele vai lecionar e também dar uma boa formação geral que nós chamamos de omnilateral". 
Q- P3 - "Nós precisamos levar em consideração esse tópico, por exemplo, os alunos que chegam aqui, como é um curso noturno muitas vezes eles trabalham de dia, chegam cansados, tem famílias mas isso não quer dizer que eles precisam ser excluídos a gente tem que preocupar com uma educação inclusiva. Os alunos já chegam acreditando que não são capazes de mudar essa realidade que eu acho que é perfeitamente possível quando queremos alguma coisa e nós discutimos exatamente sobre isso discutimos sobre isso no contexto da última reunião que nós tivemos o colegiado".

O-P1: "nós tentamos a medida do possível sempre readequar em algumas disciplinas, algumas situações cotidianas do aluno levando em consideração também alguns aspectos regionais, tentando assim na medida do possível estar fazendo essas adequações".

Tais excertos evidenciam a preocupação e compromisso dos formadores com os estudantes dos cursos de licenciaturas que provêm, na sua grande maioria, das classes econômicas baixas e médias da sociedade. Na perspectiva de uma educação para autonomia e para criticidade, é preciso propiciar a todos os homens o acesso aos conhecimentos historicamente produzidos pela humanidade, voltada ao entendimento da complexidade de toda sociedade, dentro de perspectiva política de transformação social para o desenvolvimento de todas as potencialidades dos homens, entendendo-os como sujeitos de sua própria história.

Esses atores/cidadãos advindos de classes econômicas menos favorecidas, ao participarem de processos de escolhas na esfera de formação inicial, estarão, para além do exercício de sua autonomia, se preparando e se conectando a outros processos educacionais que não se conformam à uma lógica econômica, política e social que tenham o ser humano como centralidade.

Para além dos atos de currículo advindos das entrevistas e questionário respondidos por professores formadores, foram analisados os projetos pedagógicos dos cursos com o fito de apreender se e em que medida seus objetivos formativos se articulam com uma proposta de educação politécnica.

O Quadro 1 reúne excertos advindos de 6 (seis) projetos pedagógicos de cursos (IFG, 2007, 2017, 2018a, 2018b, 2018c e 2018d). Especificamente, foram destacados as partes que guardavam estrita demarcação em torno de uma proposta de formação inicial de professores alicerçadas sob os fundamentos de uma educação na perspectiva politécnica.

Quadro 1- Objetivos formativos dos cursos de licenciatura investigados

\begin{tabular}{|c|l|}
\hline CURSO & \multicolumn{1}{c|}{ OBJETIVO } \\
\hline PPC-1 & $\begin{array}{l}\text { Geral: Objetiva a formação do educador bilíngue, que ao final do curso esteja apto a trabalhar com a } \\
\text { educação de alunos surdos e ouvintes, atendendo a todos em sua primeira língua e com metodologias } \\
\text { de ensino adequadas a ela. } \\
\text { Específico: Formar profissionais capazes de planejar, executar e avaliar processos educativos, numa } \\
\text { perspectiva inclusiva e emancipatório dos sujeitos. (IFG, 2018a, p.11, Grifos nossos) }\end{array}$ \\
\hline PPC-2 & $\begin{array}{l}\text { Objetiva formar o professor/artista/pesquisador com consciência crítica, política e ética, } \\
\text { comprometido com a formação estética e as transformações sociais, capaz de atuar na educação básica, } \\
\text { incluindo a Educação de Jovens e Adultos e educação profissional. (IFC, 2017, p.16, Grifos nossos) }\end{array}$ \\
\hline PPC-3 & $\begin{array}{l}\text { O objetivo do curso superior de Licenciatura em Química é formar o Licenciado em Química a partir } \\
\text { dos conhecimentos das áreas de Química e Educação, formando-o para a pluralidade e a diversidade } \\
\text { tanto do ponto de vista dos conteúdos específicos da química, como também dos conteúdos e } \\
\text { habilidades de cunho educativo/pedagógico, nos âmbitos teórico e experimental para que possam } \\
\text { promover a educação de forma científica e pedagógica, de forma a possibilitar a construção dos } \\
\text { conhecimentos socioeducacionais e psicológicos e desenvolver habilidades específicas para atuar de } \\
\text { forma crítica, reflexiva e inclusiva, necessárias para sua atuação como professor de Química e demais } \\
\text { atribuições. (IFG, 2018b, p.18, Grifos nossos) } \\
\text { Específico: Exercer a reflexão crítica sobre sua própria prática como educador, sendo capaz de buscar } \\
\text { e compreender novas ideias e novas tecnologias, relacionando-as ao ensino de Ciências. (IFG, 2018b, } \\
\text { p.18) }\end{array}$ \\
\hline GERAL:O Curso de Licenciatura em Física tem como objetivo principal a formação de educadores em \\
\hline
\end{tabular}




\begin{tabular}{|c|l|}
\hline & $\begin{array}{l}\text { Física com perfil para atuação no ensino de nível médio, em face da demanda de professores de Física } \\
\text { para o ensino médio na região de Jataí. O curso tem como meta oferecer aos seus graduandos as } \\
\text { condições necessárias para o magistério, tanto do ponto de vista dos conteúdos específicos da física } \\
\text { enquanto ciência, como também dos conteúdos e habilidades de cunho educativo/pedagógico, tanto } \\
\text { no âmbito teórico quanto experimental. } \\
\text { Específico: Enfrentar os desafios e peculiaridades locais e regionais, referentes ao ensino, de forma } \\
\text { comprometida com o processo de transformação da realidade circundante. (IFG,2007, p. 26, Grifos } \\
\text { nossos) }\end{array}$ \\
\hline PPC-5 & $\begin{array}{l}\text { São objetivos do curso de Licenciatura em Química formar educadores com condições necessárias } \\
\text { para desenvolver uma educação contextualizada, com foco na construção do conhecimento, nos } \\
\text { enfrentando desafios e peculiaridades locais e regionais, de forma comprometida com o processo de } \\
\text { transformação da realidade circundante, incluindo os aspectos relacionados às responsabilidades } \\
\text { sociais e ambientais; como no âmbito teórico e experimental. (IFG, 2018d, p.23, Grifos nossos) }\end{array}$ \\
\hline PPC-6 & $\begin{array}{l}\text { Objetivo Geral: visa preparar profissionais capazes de realizar atividades de docência, nas disciplinas } \\
\text { de Química, no Ensino Médio, e de Ciências, no Ensino Fundamental, oferecendo uma sólida formação } \\
\text { técnico-prática e metodológica, fundamentadas nos diversos campos da Química, privilegiando o } \\
\text { conhecimento pedagógico e a vivência de experiências relativas ao ensino, imprescindíveis à formação } \\
\text { inicial do educador. (IFG, 2018c.p.10). O licenciado em Química também poderá atuar como sujeito de } \\
\text { transformação da realidade da educação básica brasileira devendo inserir-se na instituição escolar e no } \\
\text { exercício cotidiano de sua profissão enfrentando os desafios da sala de aula, bem como as tarefas que } \\
\text { as transcendem. (p.16, Grifos nossos) }\end{array}$ \\
\hline
\end{tabular}

Assim como evidenciaram as falas dos professores, os objetivos formativos circunscritos nos projetos pedagógicos dos cursos de licenciatura também demarcam, claramente, o compromisso de preparar os licenciados para a atuação em espaços escolares e na sociedade em perspectiva educacional politécnica.

Em síntese, a análise dos dados produzidos desvelam, sobretudo, elementos matizantes de atos curriculares forjados pela reflexão crítica individual e coletiva do corpo docente e pelo compromisso com a formação de professores-trabalhadores, irrestritamente, articulada às práticas educacionais da sociedade que não se conformam com a lógica irreformável do capital (MÉSZÁROS, 2008).

\section{ALGUMAS CONSIDERAÇÕES PARA UM ARREMATE (PROVISÓRIO)}

Partindo da compreensão de que os Institutos Federais são por compromisso de lei instituições formadoras de professores-trabalhadores, este trabalho buscou evidências de permeabilidade a um projeto formativo comprometido com a educação politécnica a partir dos atos de currículo de professores formadores de cursos de licenciatura de um Instituto Federal de Educação, Ciência e Tecnologia. Neste trabalho, tratamos, empiricamente pela via das falas dos professores formadores e de análise dos objetivos formativos definidos nos projetos pedagógicos de cursos de licenciaturas, de um dos processos que perpassam a formação inicial de trabalhadores-professores, qual seja, a (re) elaboração do currículo, ou seja, do conhecimento eleito como formativo.

Tomou-se aqui como ponto de partida e de chegada, a compreensão de educação na perspectiva, e nesse sentido, compreende-se que a escola/universidade transforma direta e imediatamente a sociedade. Ela, segundo Saviani (2012) o faz agindo sobre os sujeitos da prática de modo indireto e mediato. Discutir a formação do professor, tendo por base essa concepção crítica de educação, significa a opção por uma teoria pedagógica que possui alicerces claros de sustentação, o materialismo histórico-dialético. Teoria esta que evidência ser objeto da educação, não somente a transmissão dos conteúdos clássicos, mas também o alicerce da ponte entre a escola/universidade com as necessidades históricas da classe trabalhadora.

Ante ao exposto, a discussão dos dados empíricos permitiu evidenciar os seguintes atos de currículo 1) assumência do direito e responsabilidade pela (re)definição do conhecimento eleito como formativo; 2) interação democrática (declarada) entre os professores formadores e os estudantes; 3 ) construção curricular que assume o compromisso com a emancipação humana; 4) protagonismo dos 
Núcleo Docentes Estruturantes na orquestragem do processo de (re)elaboração do projeto pedagógico do curso; 5) insignificante ocorrência de delegação de responsabilidade às instâncias superiores da instituição. Considerando os pressupostos teóricos que subjazem à uma educação na perspectiva politécnica, compreende-se que os três primeiros atos lhe são proximais (estando, portanto, na mira), e já os dois últimos, distais (na miragem), pois revela a coadjuvantivação do envolvimento de parte dos docentes que não integram os NDEs, assim como a participação dos estudantes, professorestrabalhadores em processo de formação inicial.

Cabe ainda apontar alguns limites dessa investigação no que concerne à produção e discussão de dados inerentes às outras formas de exercício da autonomia dos professores formadores; às formas e espaços concretos de participação dos estudantes e demais envolvidos nos processos (re)elaboração do currículo, bem como sobre as perspectivas decoloniais de currículo. Será nossa tarefa imediata, doravante.

Inobstante a ocorrência de atos de curriculares que tendem a coadjuvantização da ação de parte dos professores formadores e estudantes, este estudo evidencia materialidade de atos curriculares que miram à construção de um percurso de formação inicial de trabalhadores-professores pautado pelo comprometimento coletivo e democrático com a definição do seu conteúdo (currículo) em uma perspectiva educacional politécnica, o que corrobora com seu intercâmbio com um projeto de desenvolvimento social de ampliação dos processos de socialização humana, não se restringindo, portanto, ao sentido, meramente, unilateral, interessado e imediato do mercado de trabalho, e sim dialoga e endossa a consecução de um projeto de sociedade alternativo ao da lógica do capital.

\section{REFERÊNCIAS}

ARROYO, M. G. Currículo, território em disputa. Petrópolis: Vozes, 2011.

ARROYO, M. G. As relações sociais na escola e a formação do trabalhador. In: FERRATTI, C.J.; SILVA JUNIOR, J.R.; OLIVEIRA, M.R.N.S. (Orgs). Trabalho, formação e currículo: Para onde vai a escola? São Paulo: Xamã, 1999.

GRAMSCI, A. Cadernos do Cárcere. Os intelectuais. O princípio educativo. Jornalismo. V. 2, Rio de Janeiro: Civilização Brasileira, 2001.

IFG. Projeto Pedagógico do Curso de Licenciatura em Artes visuais. Cidade de Goiás. Ag. de 2017. Disponível em < http://cursos.ifg.edu.br/info/lic/lic-artes-visuais/CP-GOIAS> Acesso em: 04/10/2019.

IFG. Projeto Pedagógico do Curso de Licenciatura em Física. Jataí. 2007. Disponível em < http://cursos.ifg.edu.br/info/lic/lic-fisica/CP-JAT> Acesso em: 06/10/2019.

IFG. Projeto Pedagógico do Curso de Licenciatura em Pedagogia Bilíngue- Libras/Português. Aparecida de Goiânia. Jul. de 2018a. Disponível em: http://cursos.ifg.edu.br/info/lic/lic-pedagogia-bilingue/CP-APA. Acesso em: 04/10/2019.

IFG. Projeto Pedagógico do Curso de Licenciatura em Química. Itumbiara. Mar..2018d. Disponível em: http://cursos.ifg.edu.br/info/lic/lic-quimica/CP-ITU. Acesso em: 06/11/2019.

IFG. Projeto Pedagógico do Curso de Licenciatura em Química. Luziânia. Jun.2018c. Disponível em: http://cursos.ifg.edu.br/info/lic/lic-quimica/CP-LUZIANI. Acesso em: 06/11/2019.

IFG. Projeto Pedagógico do Curso de Licenciatura em Química. Uruaçu. 2018b. Disponível em: http://cursos.ifg.edu.br/info/lic/lic-quimica/CP-URUACU. Acesso em: 04/10/2019.

MACEDO, R. S. Atos de currículo formação em ato?: Para compreender, entretecer e problematizar currículo e formação. Ilhéus: Editus, 2011.

MACEDO, R. S. Atos de currículos: uma incessante atividade etnometódica e fonte de análise de práticas curriculares. Currículo sem Fronteiras, v. 13, n. 3, p. 427-435, set./dez. 2013. Disponível em:

http://www.curriculosemfronteiras.org/vol13iss3articles/macedo.pdf. Acesso em 15/04/2020.

MACHADO, J.M.H. Processo de Vigilância em Saúde do Trabalhador, Cadernos de Saúde Pública, Rio de 
Janeiro, 13 (sup.2), 1997, p.33-45. Disponível em: https://www.scielo.br/scielo.php?pid=S0102311X1997000600004\&script=sci_abstract\&tlng=pt. Acesso em 15/04/2020.

MARX. K. ENGELS, F. A ideologia alemã. São Paulo: Boitempo. 2007.

MÉSZÁROS, I. A educação para além do capital. 2.ed. São Paulo: Boitempo Editorial, 2008.

OLIVEIRA, M. M. Como fazer pesquisa qualitativa. Petrópolis: Vozes, 2007.

QUELHAS, A. A.; NOZAKI, H.T. Políticas neoliberais e as modificações na formação do professor de educação física: em defesa da politécnica. In: VI Seminário da REDESTRADO: regulação educacional e trabalho docente, 2006, Rio de Janeiro. Anais... Rio de Janeiro: Universidade do Estado do Rio de Janeiro, 2006, p 1-8.

RODRIGUES, J. Educação politécnica. In: PEREIRA, I.B. e LIMA, J.C.F. (Org.). Dicionário da Educação Profissional em Saúde. 2 ed. Rio de Janeiro: Escola Politécnica de Saúde Joaquim Venâncio, 2009. Disponível em: http://www.epsjv.fiocruz.br/dicionario/verbetes/edupol.html. Acesso em: 20/04/2020.

SAVIANI, D. O choque teórico da politécnica. Trabalho, Educação e Saúde, 1(1), p. 131-152, 2003.

SAVIANI, D. Pedagogia Histórico-Crítica. 11.ed. Campinas: Autores Associados, 2012.

SAVIANI, D. Sobre a concepção de politécnica. Rio de Janeiro: Fiocruz, 1989.

SILVA, K. A. C. P. C. A formação de professores na perspectiva crítico-emancipadora. Linhas Críticas

(UnB), v. 17, 2011, p. 13-31.

TRIVIÑOS, A. N. S. Introdução à pesquisa em ciências sociais: A pesquisa qualitativa em educação. São Paulo: Atlas. 2017.

\section{AGRADECIMENTOS}

Agradeço ao Programa Institucional de Apoio à Produtividade em Pesquisa do Instituto Federal de Educação, Ciência e Tecnologia de Goiás pelo apoio financeiro ao projeto de pesquisa intitulado "Projetos político-pedagógicos das licenciaturas dos Institutos Federais do Estado de Goiás: o vir-a-ser de professores para a educação básica".

Este obra está licenciado com uma Licença Creative Commons Atribuição-NãoComercial 4.0 Internacional. 